\title{
Racial Differences in Clinical Use of Cinacalcet in a Large Population of Hemodialysis Patients
}

\author{
Britt B. Newsome ${ }^{a}$ Ryan D. Kilpatrick ${ }^{b}$ Jiannong Liu ${ }^{c}$ David Zaun ${ }^{c}$ \\ Craig A. Solid ${ }^{c}$ Kimberly Nieman ${ }^{c}$ Wendy L. St. Peter ${ }^{c, d}$ \\ aDenver Nephrology Clinical Research Division, Denver, Colo., benter for Observational Research, Amgen Inc., \\ Thousand Oaks, Calif., 'Chronic Disease Research Group, Minneapolis Medical Research Foundation, and \\ ${ }^{d}$ College of Pharmacy, University of Minnesota, Minneapolis, Minn., USA
}

\section{Key Words}

Cinacalcet · Hemodialysis · Racial differences · Secondary hyperparathyroidism

\begin{abstract}
Background/Aims: African-Americans with end-stage renal disease receiving dialysis have more severe secondary hyperparathyroidism than Whites. We aimed to assess racial differences in clinical use of cinacalcet. Methods: This retrospective cohort study used data from DaVita, Inc., for 45,589 prevalent hemodialysis patients, August 2004, linked to Centers for Medicare \& Medicaid Services data, with follow-up through July 2007. Patients with Medicare as primary payer, intravenous vitamin D use, or weighted mean parathyroid hormone (PTH) level $>150 \mathrm{pg} / \mathrm{ml}$ at baseline (August 1-October 31,2004$)$ were included. Cox proportional hazard modeling was used to evaluate race and other demographic and clinical characteristics as predictors of cinacalcet initiation, titration, and discontinuation. Results: Of 16,897 included patients, 7,674 (45.4\%) were African-American and 9,223 (54.6\%) were white; $53.2 \%$ of cinacalcet users were AfricanAmerican. Cinacalcet was prescribed for $47.7 \%$ of AfricanAmericans and $34.5 \%$ of Whites, and for a greater percentage of African-Americans at higher doses at each PTH strata.
\end{abstract}

After covariate adjustment, African-Americans were more likely than Whites to receive cinacalcet prescriptions (hazard ratio $1.17, p<0.001)$. The direction and magnitude of this effect appeared to vary by age, baseline PTH, and calcium, and by elemental calcium use. African-Americans were less likely than Whites to have prescriptions discontinued and slightly more likely to undergo uptitration (hazard ratio 1.09, 95\% confidence interval 0.995-1.188), but this relationship lacked statistical significance. Conclusion: Cinacalcet is prescribed more commonly and at higher initial doses for African-Americans than for Whites to manage secondary hyperparathyroidism.

C 2013 S. Karger AG, Basel

\section{Introduction}

African-Americans have a substantially increased risk of end-stage renal disease (ESRD) compared with Whites and are disproportionately represented in the ESRD population [1]. African-Americans with ESRD also have a higher burden of some ESRD-related complications, including secondary hyperparathyroidism (SHPT) $[2,3]$.

Racial differences in regulation of the parathyroid hormone $(\mathrm{PTH}) /$ vitamin $\mathrm{D}$ axis have been described in the

\section{KARGER}

E-Mail karger@karger.com

www.karger.com/ajn
(C) 2013 S. Karger AG, Basel

0250-8095/13/0382-0104\$38.00/0
Wendy L. St. Peter, PharmD

Chronic Disease Research Group, Minneapolis Medical Research Foundation 914 South 8th Street, Suite S4.100

Minneapolis, MN 55404 (USA)

E-Mail WStPeter@cdrg.org 
general population; studies demonstrate lower levels of 25-hydroxyvitamin D and higher levels of PTH in African-Americans $[4,5]$. African-Americans with chronic kidney disease not receiving dialysis, as well as those with ESRD, are more likely to have SHPT, independent of other factors such as age and sex $[2,6,7]$; average maximum PTH levels among African-American ESRD patients are nearly twice those of white ESRD patients [6].

Not surprisingly, given their higher PTH levels, African-Americans with ESRD are more likely to receive activated vitamin $\mathrm{D}$, and to receive higher and more consistent doses, to treat SHPT $[2,3]$. Representing an alternative therapy for SHPT, calcimimetics increase the sensitivity of calcium-sensing receptors to extracellular calcium [8]. Although the first calcimimetic, cinacalcet hydrochloride (Sensipar/Mimpara), was approved for clinical use in May 2004, many aspects of its clinical use have not been fully described. Despite higher prevalence and greater severity of SHPT among African-Americans, racial differences in use of cinacalcet have not been assessed.

Due to the higher levels of PTH and higher use of intravenous activated vitamin D among African-American dialysis patients, we hypothesized that use of cinacalcet to treat SHPT would also be higher in these patients than in their white counterparts. We further hypothesized that the likelihood of cinacalcet prescription initiation and uptitration would be higher for African-Americans, and the likelihood of discontinuation would be lower.

\section{Methods}

Laboratory and medication use data were obtained from the electronic medical records of DaVita, Inc. Variables included laboratory values (PTH, calcium, phosphorus, albumin, hemoglobin, white blood cell count); weight and height, from which we calculated body mass index (BMI); vascular access; Kt/V; and use and doses of intravenous (IV) vitamin $\mathrm{D}$, cinacalcet, and phosphate binders. These data were linked with the Centers for Medicare \& Medicaid Services (CMS) ESRD dataset, from which demographic characteristic (age, race, and sex), geographic region, primary ESRD cause, dialysis duration, comorbid condition, and hospitalization information was obtained. Database linkage, details of the variables obtained from each database, and creation of drug files have been previously described $[8,9]$.

The study population was selected from a cohort of 45,589 prevalent adult hemodialysis patients. The following inclusion criteria were applied: aged at least 18 years on August 1, 2004, survived the 3-month baseline period (August 1, 2004-October 31, 2004), had Medicare as primary payer, had not undergone kidney transplant before November 1, 2004, showed evidence of SHPT from use of IV vitamin D or recorded PTH $>300 \mathrm{pg} / \mathrm{ml}$ before No- vember 1, $2004(\mathrm{n}=25,250)$; exclusion criteria further limited the cohort to white or African-American patients $(n=23,106)$ and patients with a weighted mean 3-month baseline PTH $>150 \mathrm{pg} / \mathrm{ml}$, with weighting as follows: 1 for 1 month before, 0.5 for 2 months before, and 0.33 for 3 months before November 1, 2004. This gave a final sample of 16,897 patients included in the analyses.

The study outcomes were cinacalcet initiation (first cinacalcet prescription), cinacalcet dose uptitration (first dosage increase), and cinacalcet discontinuation (prescription discontinuation). The analysis of cinacalcet initiation included all patients and followed them from November 1, 2004, to the earliest date of death, kidney transplant, change to peritoneal dialysis, transfer out of a DaVita facility, cinacalcet initiation, or July 31, 2007. The analyses of dose uptitration and discontinuation included only cinacalcet users, who were followed from the cinacalcet initiation date to the earliest date of death, kidney transplant, change to peritoneal dialysis, transfer out of a DaVita facility, cinacalcet dose uptitration/ discontinuation, or July 31, 2007.

Patient characteristics were derived at specific time points: on November 1, 2004, and at cinacalcet initiation, dose uptitration, and discontinuation. A 3-month period before each time point was used to assess medication use and laboratory values. For laboratory values, the last measurement in the 3 -month period was used. Patient characteristics derived from the 3 -month period August 1, 2004, to October 31, 2004, were considered the values at baseline. Preinitiation laboratory values were those occurring before and most proximal to the first cinacalcet prescription. Hospital days were derived using the 6 months before the time point (baseline, initiation, uptitration, and discontinuation) and comorbidity values were derived from both the ESRD Medical Evidence Report (form CMS-2728) and from 6 months before the time point.

This study includes descriptive and predictive analyses. Mean initial cinacalcet doses were determined. Cinacalcet doses were categorized as $\leq 30,>30$ to $\leq 60,>60$ to $\leq 90$, and $>90 \mathrm{mg}$. Weekly paricalcitol equivalent IV vitamin D doses were calculated using a previously described method [10]. Consistency of vitamin D use was also evaluated; consistent use was defined as $\geq 80 \%$ of hemodialysis treatments with vitamin $\mathrm{D}$ administration and inconsistent use as $>0$ to $<80 \%$ of treatments.

Among cinacalcet patients with no titration events after initiation, cinacalcet doses at the initial prescription were compared between African-American and white patients, overall and by baseline PTH group. Means and standard deviations were reported and the $\mathrm{z}$-test was performed for the comparison. Cox proportional hazard modeling was used to evaluate race and other demographic, clinical, and laboratory characteristics as predictors of cinacalcet initiation, titration, and discontinuation. Interactions between race and other covariates were tested in each model. All analyses were conducted using SAS 9.1 (SAS Institute, Inc., Cary, N.C., USA).

\section{Results}

Of the 16,897 patients included in the analysis, 7,674 (45.4\%) were African-American. Table 1 shows patient characteristics at baseline (November 1, 2004). Among all patients, regardless of cinacalcet use, African-Americans 
Table 1. Baseline (November 1, 2004) characteristics by race

\begin{tabular}{|c|c|c|}
\hline Patient characteristics & $\begin{array}{l}\text { African-Americans } \\
(\mathrm{n}=7,674)\end{array}$ & $\begin{array}{l}\text { Whites } \\
(\mathrm{n}=9,223)\end{array}$ \\
\hline \multicolumn{3}{|l|}{ Demographics } \\
\hline Age, years & $59.6 \pm 14.6$ & $65.8 \pm 14.7$ \\
\hline \multicolumn{3}{|l|}{ Age group } \\
\hline $18-44$ years & $1,264(16.5)$ & $904(9.8)$ \\
\hline $45-6$ years & $3,230(42.1)$ & $2,864(31.1)$ \\
\hline $65-74$ years & $1,937(25.2)$ & $2,421(26.2)$ \\
\hline$\geq 75$ years & $1,243(16.2)$ & $3,034(32.9)$ \\
\hline \multicolumn{3}{|l|}{ Region } \\
\hline East North Central & $849(11.1)$ & $977(10.6)$ \\
\hline East South Central & $52(0.7)$ & $150(1.6)$ \\
\hline Middle Atlantic, New England & $784(10.2)$ & $887(9.6)$ \\
\hline Mountain & $191(2.5)$ & $646(7.0)$ \\
\hline Pacific & $859(11.2)$ & $2,386(25.9)$ \\
\hline South Atlantic & $3,457(45.0)$ & $1,825(19.8)$ \\
\hline West North Central & $273(3.6)$ & $819(8.9)$ \\
\hline West South Central & $1,204(15.7)$ & $1,516(16.4)$ \\
\hline \multicolumn{3}{|l|}{ Primary cause of ESRD } \\
\hline Diabetes & $3,182(41.5)$ & $4,369(47.4)$ \\
\hline Hypertension & $2,956(38.5)$ & $2,282(24.7)$ \\
\hline Glomerulonephritis & $701(9.1)$ & $921(10.0)$ \\
\hline Other & $835(10.9)$ & $1,651(17.9)$ \\
\hline Women & $3,756(48.9)$ & $4,030(43.7)$ \\
\hline Dialysis duration, years & $4.5 \pm 4.1$ & $3.7 \pm 4.0$ \\
\hline BMI & $27.5 \pm 7.1$ & $26.8 \pm 6.3$ \\
\hline Hospital days & $5.64 \pm 11.3$ & $5.35 \pm 11.1$ \\
\hline \multicolumn{3}{|l|}{ Vascular access } \\
\hline Arteriovenous fistula & $2,458(32.0)$ & $3,706(40.2)$ \\
\hline Graft & $3,371(43.9)$ & $3,278(35.5)$ \\
\hline Catheter & $1,449(18.9)$ & $1,881(20.4)$ \\
\hline Other/unknown & $396(5.2)$ & $358(3.9)$ \\
\hline \multicolumn{3}{|l|}{ Laboratory } \\
\hline Median intact PHT, pg/ml & 301.9 & 255.8 \\
\hline Corrected calcium, mg/dl & $9.6 \pm 0.7$ & $9.5 \pm 0.7$ \\
\hline Phosphorus, $\mathrm{mg} / \mathrm{dl}$ & $5.5 \pm 1.6$ & $5.5 \pm 1.6$ \\
\hline Albumin, mg/dl & $3.9 \pm 0.4$ & $3.9 \pm 0.4$ \\
\hline Hemoglobin, mg/dl & $12.4 \pm 1.4$ & $12.4 \pm 1.3$ \\
\hline White blood cell count, $/ \mathrm{mm}^{3}$ & $6,474.1 \pm 2,357.8$ & $7,250.8 \pm 2,433.5$ \\
\hline $\mathrm{Kt} / \mathrm{V}$ & $1.6 \pm 0.3$ & $1.7 \pm 0.3$ \\
\hline \multicolumn{3}{|l|}{ Medications } \\
\hline IV vitamin $\mathrm{D}$ dose, $\mu \mathrm{g}^{\mathrm{a}}$ & $14.5 \pm 10.3$ & $9.1 \pm 7.5$ \\
\hline Lanthanum carbonate, mg & $4,450.5 \pm 0.0$ & $395.6 \pm 0.0$ \\
\hline Sevelamer hydrochloride, $\mathrm{mg}$ & $7,029.5 \pm 3,971.7$ & $6,807.3 \pm 4,202.0$ \\
\hline Calcium acetate, $\mathrm{mg}$ & $1,193.7 \pm 678.8$ & $1,077.8 \pm 646.2$ \\
\hline Calcium carbonate, mg & $1,592.9 \pm 1,409.4$ & $1,398.2 \pm 1,139.3$ \\
\hline Elemental calcium, mg & $1,418.4 \pm 1,118.8$ & $1,262.3 \pm 943.2$ \\
\hline \multicolumn{3}{|l|}{ Comorbid illness } \\
\hline Congestive heart failure & $3,470(45.2)$ & $4,491(48.7)$ \\
\hline Atherosclerotic heart disease & $2,751(35.8)$ & $4,600(49.9)$ \\
\hline Peripheral vascular disease & $2,586(33.7)$ & $3,718(40.3)$ \\
\hline Cerebrovascular accident/transient ischemic attack & $1,317(17.2)$ & $1,642(17.8)$ \\
\hline Dysrhythmia & $1,656(21.6)$ & $2,772(30.1)$ \\
\hline Other cardiovascular disease & $2,293(29.9)$ & $3,033(32.9)$ \\
\hline Cancer & $552(7.2)$ & $870(9.4)$ \\
\hline Chronic obstructive pulmonary disease & $1,152(15.0)$ & $1,841(20.0)$ \\
\hline Diabetes & $4,534(59.1)$ & $5,664(61.4)$ \\
\hline Gastrointestinal disease & $545(7.1)$ & $610(6.6)$ \\
\hline Liver disease & $317(4.1)$ & $380(4.1)$ \\
\hline
\end{tabular}

Values are mean \pm SD or $\mathrm{n}(\%) .{ }^{\text {a }}$ Weekly paricalcitol equivalent. 
Table 2. Characteristics of cinacalcet users and non-users at baseline and users at initiation, by race

\begin{tabular}{|c|c|c|c|c|c|c|}
\hline \multirow[t]{2}{*}{ Patient characteristics } & \multicolumn{3}{|c|}{ African-Americans } & \multicolumn{3}{|l|}{ Whites } \\
\hline & $\begin{array}{l}\text { cinacalcet } \\
(\mathrm{n}=3,422)\end{array}$ & $\begin{array}{l}\text { non-cinacalcet } \\
(\mathrm{n}=4,252)\end{array}$ & $\begin{array}{l}\text { at initiation } \\
\text { cinacalcet } \\
(\mathrm{n}=3,662)\end{array}$ & $\begin{array}{l}\text { cinacalcet } \\
(\mathrm{n}=2,785)\end{array}$ & $\begin{array}{l}\text { non-cinacalcet } \\
(\mathrm{n}=6,438)\end{array}$ & $\begin{array}{l}\text { at initiation } \\
\text { cinacalcet } \\
(\mathrm{n}=3,182)\end{array}$ \\
\hline \multicolumn{7}{|l|}{ Demographics } \\
\hline Age, years & $56.8 \pm 14.3$ & $61.8 \pm 14.6$ & $56.9 \pm 14.2$ & $60.0 \pm 15.2$ & $68.3 \pm 13.7$ & $60.0 \pm 15.2$ \\
\hline \multicolumn{7}{|l|}{ Age group } \\
\hline $45-64$ years & $1,583(46.3)$ & $1,647(38.7)$ & $1,694(46.3)$ & $1,139(40.9)$ & $1,725(26.8)$ & $1,295(40.7)$ \\
\hline $65-74$ years & $780(22.8)$ & $1,157(27.2)$ & $840(22.9)$ & $623(22.4)$ & $1,798(27.9)$ & $723(22.7)$ \\
\hline$\geq 75$ years & $364(10.6)$ & $879(20.7)$ & $391(10.7)$ & $540(19.4)$ & $2,494(38.7)$ & $613(19.3)$ \\
\hline Women & $1,713(50.1)$ & $2,043(48.0)$ & $1,846(50.4)$ & $1,270(45.6)$ & $2,760(42.9)$ & $1,455(45.7)$ \\
\hline Dialysis duration, years & $4.9 \pm 4.3$ & $4.2 \pm 3.9$ & $4.8 \pm 4.2$ & $4.6 \pm 4.7$ & $3.3 \pm 3.6$ & $4.5 \pm 4.7$ \\
\hline Hospital days & $4.84 \pm 10.4$ & $6.28 \pm 12.03$ & $4.88 \pm 10.5$ & $4.01 \pm 8.98$ & $5.93 \pm 11.86$ & $4.20 \pm 9.27$ \\
\hline Albumin, mg/dl & $3.9 \pm 0.4$ & $3.8 \pm 0.4$ & $3.9 \pm 0.4$ & $3.9 \pm 0.4$ & $3.8 \pm 0.4$ & $3.9 \pm 0.4$ \\
\hline Hemoglobin, mg/dl & $12.4 \pm 1.4$ & $12.3 \pm 1.5$ & $12.4 \pm 1.4$ & $12.4 \pm 1.3$ & $12.3 \pm 1.3$ & $12.4 \pm 1.3$ \\
\hline White blood cell count, $/ \mathrm{mm}^{3}$ & $6,416.2 \pm 2,060.8$ & $6,521.0 \pm 2,572.2$ & $6,335.2 \pm 2,011.9$ & $7,126.1 \pm 2,257.6$ & $7,304.8 \pm 2,504.1$ & $7,134.2 \pm 2,460.5$ \\
\hline $\mathrm{Kt} / \mathrm{V}$ & $1.6 \pm 0.3$ & $1.6 \pm 0.3$ & $1.6 \pm 0.3$ & $1.7 \pm 0.3$ & $1.7 \pm 0.4$ & $1.7 \pm 0.3$ \\
\hline \multicolumn{7}{|l|}{ Medications } \\
\hline $\begin{array}{l}\text { IV vitamin } \mathrm{D} \text { dose, } \mu \mathrm{g}^{\mathrm{a}} \\
\text { IV vitamin } \mathrm{D}\end{array}$ & $16.5 \pm 11.3$ & $12.8 \pm 9.2$ & $16.6 \pm 11.8$ & $10.8 \pm 8.5$ & $8.2 \pm 6.8$ & $11.3 \pm 9.1$ \\
\hline No use $(0 \%)$ & $138(4.0)$ & $305(7.2)$ & $185(5.1)$ & $329(11.8)$ & $1,230(19.1)$ & $375(11.8)$ \\
\hline Inconsistent use $(0<\mathrm{X}<80 \%)$ & $1,048(30.6)$ & $1,089(25.6)$ & $1,219(33.3)$ & $940(33.8)$ & $1,737(27.0)$ & $1,253(39.4)$ \\
\hline Consistent use $(\geq 80 \%)$ & $2,236(65.3)$ & $2,858(67.2)$ & $2,258(61.7)$ & $1,516(54.4)$ & $3,471(53.9)$ & $1,554(48.8)$ \\
\hline Lanthanum carbonate, $\mathrm{mg}$ & & $4,450.5 \pm 0.0$ & $1,874.0 \pm 1,539.1$ & $395.6 \pm 0.0$ & & $1,992.1 \pm 1,621.4$ \\
\hline
\end{tabular}

Values are mean $\pm \mathrm{SD}$ or $\mathrm{n}(\%) .{ }^{\mathrm{a}}$ Weekly paricalcitol equivalent.

were younger than Whites and more likely to be women. Regionally, African-Americans were more often represented in the South Atlantic region and less often in the Mountain, Pacific, and West North Central regions. African-Americans were more likely to have hypertension as a primary cause of ESRD and less likely to have diabetes and other causes. Mean dialysis duration was longer and BMI higher for African-Americans; they had slightly more hospital days and were less likely to have an arteriovenous fistula at baseline. Regarding SHPT-related laboratory values, median intact PTH was higher for African-Americans (302 vs. $256 \mathrm{pg} / \mathrm{ml}$ ), mean corrected calcium was slightly higher (9.6 vs. $9.5 \mathrm{mg} / \mathrm{dl}$ ), and mean phosphorous was equivalent ( 5.5 vs. $5.5 \mathrm{mg} / \mathrm{dl}$ ). Prescribed mean weekly doses of IV vitamin D were higher for African-Americans $(14.5$ vs. $9.1 \mu \mathrm{g})$. Prescribed doses of every type of phosphorous binder were higher for African-Americans than for Whites. Comorbid illness, except gastrointestinal and liver diseases, was less likely in African-Americans.

Compared with white cinacalcet users at baseline, African-Americans had higher median intact PTH (354 vs. $317 \mathrm{pg} / \mathrm{ml})$, slightly higher mean corrected calcium (9.8 vs. $9.7 \mathrm{mg} / \mathrm{dl}$ ), and slightly lower mean phosphorous (5.7 vs. $5.9 \mathrm{mg} / \mathrm{dl}$ ) levels (table 2). Reflecting racial differences in the overall study population regardless of cinacalcet prescription, African-Americans with cinacalcet pre- 
scriptions also received higher mean weekly doses of IV vitamin D (16.5 vs. $10.8 \mu \mathrm{g}$ ), and a higher percentage used IV vitamin D consistently ( $\geq 80 \%$ of treatments). Compared with Whites, African-American cinacalcet users received prescriptions for, on average, slightly lower doses of lanthanum carbonate and sevelamer hydrochloride, but higher doses of calcium-based binders (calcium acetate and calcium carbonate).

Between baseline (November 1, 2004) and cinacalcet initiation, the median PTH level increased from 354 to $583 \mathrm{pg} / \mathrm{ml}$ (increase of $229 \mathrm{pg} / \mathrm{ml}$ ) for African-American cinacalcet patients and from 317 to $504 \mathrm{pg} / \mathrm{ml}$ (increase of $187 \mathrm{pg} / \mathrm{ml}$ ) for Whites. Mean corrected calcium levels decreased slightly from 9.8 to $9.7 \mathrm{mg} / \mathrm{dl}$ for AfricanAmericans but did not change for Whites. Mean phosphorous levels increased from 5.7 to $6.0 \mathrm{mg} / \mathrm{dl}$ for African-Americans and from 5.9 to $6.2 \mathrm{mg} / \mathrm{dl}$ for Whites. Mean weekly IV vitamin D dose (weekly paricalcitol equivalents) increased only slightly from 16.5 to $16.6 \mu \mathrm{g}$ for African-Americans but from 10.8 to $11.3 \mu \mathrm{g}$ for Whites. At the time of initiation, cinacalcet was prescribed for $47.7 \%(3,662)$ of African-Americans and $34.5 \%(3,182)$ of Whites.

Among cinacalcet patients with no titration events after initiation, African-Americans received higher mean cinacalcet doses than Whites at the time of the initial prescription (34.8 vs. $32.7 \mathrm{mg}$ ) (fig. 1); this was true at each strata of PTH. Among patients with any uptitration event during the first 12 months of therapy, average cinacalcet doses were higher for African-Americans each month and median PTH levels were persistently higher (fig. 2); a greater percentage of African-Americans continued to use cinacalcet (data not shown).

After adjustment for patient characteristics, AfricanAmericans overall were more likely than Whites to be initiated on cinacalcet (hazard ratio (HR), 1.17, p < 0.0001). However, interaction models showed that this racial disparity differed among subgroups defined by age, baseline PTH level, calcium level, and daily elemental calcium phosphate binder dose (table 3 ). By age, the largest difference occurred in the oldest group ( $\geq 75$ years, HR 1.36). As age decreased, differences were reduced; in the youngest group ( $<45$ years), likelihood of cinacalcet initiation was lower for African-Americans than for Whites (HR $0.85)$. African-Americans and Whites in high PTH $(>600$ $\mathrm{pg} / \mathrm{ml})$ and high calcium $(>10.2 \mathrm{mg} / \mathrm{dl})$ groups did not differ, but in lower PTH and calcium groups, AfricanAmericans were more likely than Whites to be initiated on cinacalcet. The likelihood of cinacalcet initiation was similar for African-Americans and Whites who were not

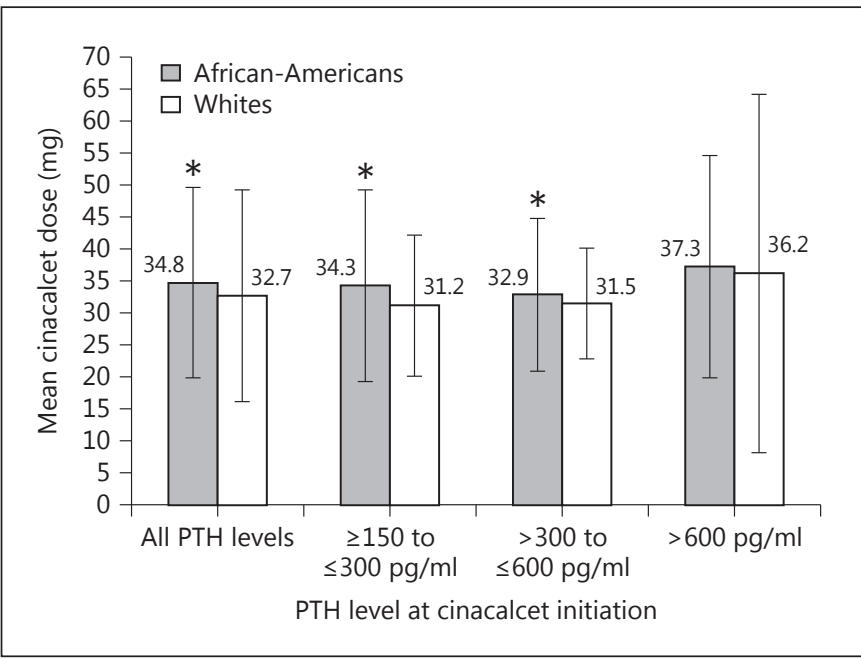

Fig. 1. Mean and standard deviation initial cinacalcet dose by race and PTH level in patients with no uptitration. Patients were categorized by PTH level at the time of cinacalcet initiation based on a weighted mean PTH level during the 3 months before initiation with weighting as follows: 1 for 1 month before, 0.5 for 2 months before, and 0.33 for 3 months before initiation. * The difference in cinacalcet doses between African-American and white patients was statistically significantly, with $\mathrm{p}<0.05$.

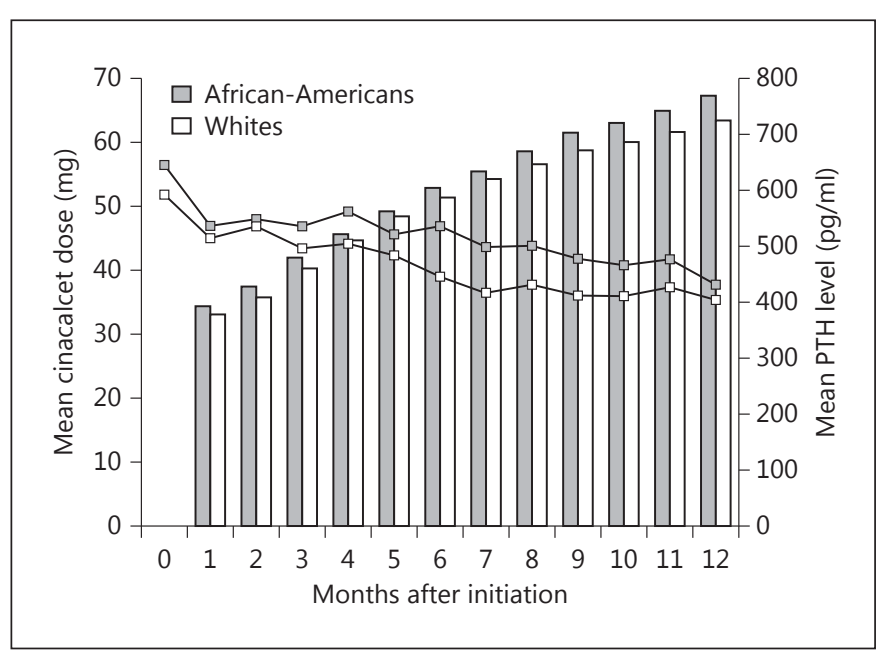

Fig. 2. Mean cinacalcet dose (bars) and median PTH level (lines) after initiation in patients with uptitration.

using calcium-containing phosphate binders, but among patients who were using these products, African-Americans were more likely to be initiated on cinacalcet.

Of patients who were initiated on cinacalcet, 1,452 African-Americans (65.7\%) experienced a dose uptitration during the 12 months of follow-up, compared with 1,098 
Table 3. Adjusted ${ }^{a}$ African-American versus white HRs (95\% CIs) for cinacalcet initiation, uptitration, and discontinuation

\begin{tabular}{|c|c|c|}
\hline Cinacalcet event & HR $(95 \% \mathrm{CI})$ & $\begin{array}{l}\mathrm{p} \text { for interac- } \\
\text { tion with race }\end{array}$ \\
\hline \multicolumn{3}{|l|}{ Initiation } \\
\hline \multicolumn{3}{|c|}{ Significant interactions with race } \\
\hline \multicolumn{2}{|c|}{ Age group } & \multirow[t]{5}{*}{$<0.001$} \\
\hline $18-44$ years & $0.85(0.75-0.96)$ & \\
\hline $45-64$ years & $1.10(1.01-1.19)$ & \\
\hline $65-74$ years & $1.33(1.19-1.48)$ & \\
\hline$\geq 75$ years & $1.36(1.19-1.56)$ & \\
\hline \multicolumn{2}{|l|}{ Intact PTH, pg/ml } & \multirow[t]{4}{*}{0.048} \\
\hline$\geq 150$ to $\leq 300$ & $1.26(1.16-1.36)$ & \\
\hline$>300$ to $\leq 600$ & $1.10(1.01-1.20)$ & \\
\hline$>600$ & $0.95(0.84-1.07)$ & \\
\hline \multicolumn{2}{|c|}{ Corrected calcium, mg/dl } & \multirow[t]{4}{*}{0.0348} \\
\hline$\geq 9.0$ to $\leq 10.2$ & $1.18(1.10-1.26)$ & \\
\hline$<9.0$ & $1.18(1.00-1.39)$ & \\
\hline$>10.2$ & $0.99(0.89-1.10)$ & \\
\hline \multicolumn{2}{|c|}{ Daily elemental calcium dose, $\mathrm{mg}$} & \multirow[t]{4}{*}{0.0123} \\
\hline None & $1.05(0.97-1.13)$ & \\
\hline $0-1,500$ & $1.16(1.04-1.30)$ & \\
\hline$>1,500$ & $1.27(1.15-1.41)$ & \\
\hline Uptitration & $1.09(0.995-1.188)$ & 0.0644 \\
\hline \multicolumn{3}{|l|}{ Discontinuation } \\
\hline \multicolumn{3}{|c|}{ Significant interactions with race } \\
\hline \multicolumn{2}{|c|}{ Intact PTH, pg/ml } & \multirow[t]{4}{*}{0.0339} \\
\hline$\geq 150$ to $\leq 300$ & $0.71(0.56-0.99)$ & \\
\hline$>300$ to $\leq 600$ & $0.741(0.65-0.85)$ & \\
\hline$>600$ & $0.945(0.80-1.11)$ & \\
\hline
\end{tabular}

${ }^{a}$ Adjusted for age, sex, region, cause of ESRD, dialysis duration, BMI, hospital days, vascular access type, intact PTH, corrected calcium, phosphorous, albumin, hemoglobin, white blood cell count, $\mathrm{Kt} / \mathrm{V}$, binder dose, daily elemental calcium dose, IV vitamin D dose, and comorbid conditions. $\mathrm{CI}=$ Confidence interval.

Whites (52.7\%) (table 4). In both race groups, patients experiencing uptitration were younger, less likely to have diabetes or glomerulonephritis as cause of ESRD, more likely to be male, and more likely to have longer dialysis duration and higher BMI (data not shown). These patients were less likely than patients with no uptitration to have comorbid conditions except for cancer (data not shown), and were more likely to have had higher median PTH levels before cinacalcet initiation (table 4). AfricanAmericans who experienced uptitration had larger absolute increases in median PTH levels (from 644.2 to 660.6 $\mathrm{pg} / \mathrm{ml} ; 16.4 \mathrm{pg} / \mathrm{ml}$ ) from the time before cinacalcet initiation to the uptitration, compared with Whites (from 580.9 to $586.5 \mathrm{pg} / \mathrm{ml} ; 5.6 \mathrm{pg} / \mathrm{ml}$ ). Serum phosphorous and calcium levels, as well as mean IV vitamin D doses, were higher at the time of cinacalcet initiation for AfricanAmericans and Whites who experienced uptitration than for those who did not. Before initiation, mean doses of all phosphorous binders were higher for African-Americans and Whites who experienced uptitration than for those who did not. Regardless of uptitration status, the mean sevelamer dose was lower for African-Americans than for Whites, and the mean elemental calcium dose was higher. After adjustment, African-Americans receiving cinacalcet were slightly more likely than Whites to experience uptitration (HR 1.09, 95\% confidence interval 0.9951.188) (table 3).

Among African-Americans who were initiated on cinacalcet, prescriptions were discontinued for 981 (36.6\%), compared with 1,035 Whites (48.2\%) (table 5). Compared with patients who continued cinacalcet, African-Americans and Whites who discontinued were older and more likely to have diabetes as cause of ESRD, shorter dialysis duration, and arteriovenous fistula as vascular access (data not shown). African-Americans who discontinued cinacalcet were more likely than those who continued to have diabetes as primary cause of ESRD, lower $\mathrm{BMI}$, and more hospital days; these patterns were the opposite among Whites (data not shown). We found no consistent pattern of comorbid illnesses. African-Americans who discontinued cinacalcet had diabetes and cancer more frequently and atherosclerotic heart disease, cerebrovascular accident/transient ischemic attack, dysrhythmia, and other cardiovascular diseases less frequently. Whites who discontinued were more likely to have atherosclerotic heart disease, peripheral vascular disease, cerebrovascular accident/transient ischemic attack, dysrhythmia, cancer, chronic obstructive pulmonary disease, and diabetes (data not shown). In both race groups, preinitiation median $\mathrm{PTH}$, serum phosphorous, and calcium levels were lower for patients whose cinacalcet prescriptions were discontinued than for those who continued (table 5). Furthermore, in both race groups, levels of PTH, serum calcium, and phosphorous decreased from the time before initiation to the time of discontinuation, and IV vitamin D doses at the time of initiation were lower for patients who discontinued cinacalcet than for those who continued; the mean IV vitamin D dose decreased slightly in both race groups from the time period before cinacalcet initiation to discontinuation. The mean dose of most phosphorous binders was lower before cinacalcet initiation for patients whose prescriptions were discontinued than for those who continued, except that the mean dose of calcium acetate was higher 
Table 4. Laboratory characteristics and medications at time of cinacalcet initiation and uptitration by race and uptitration status within 12 months of initiation

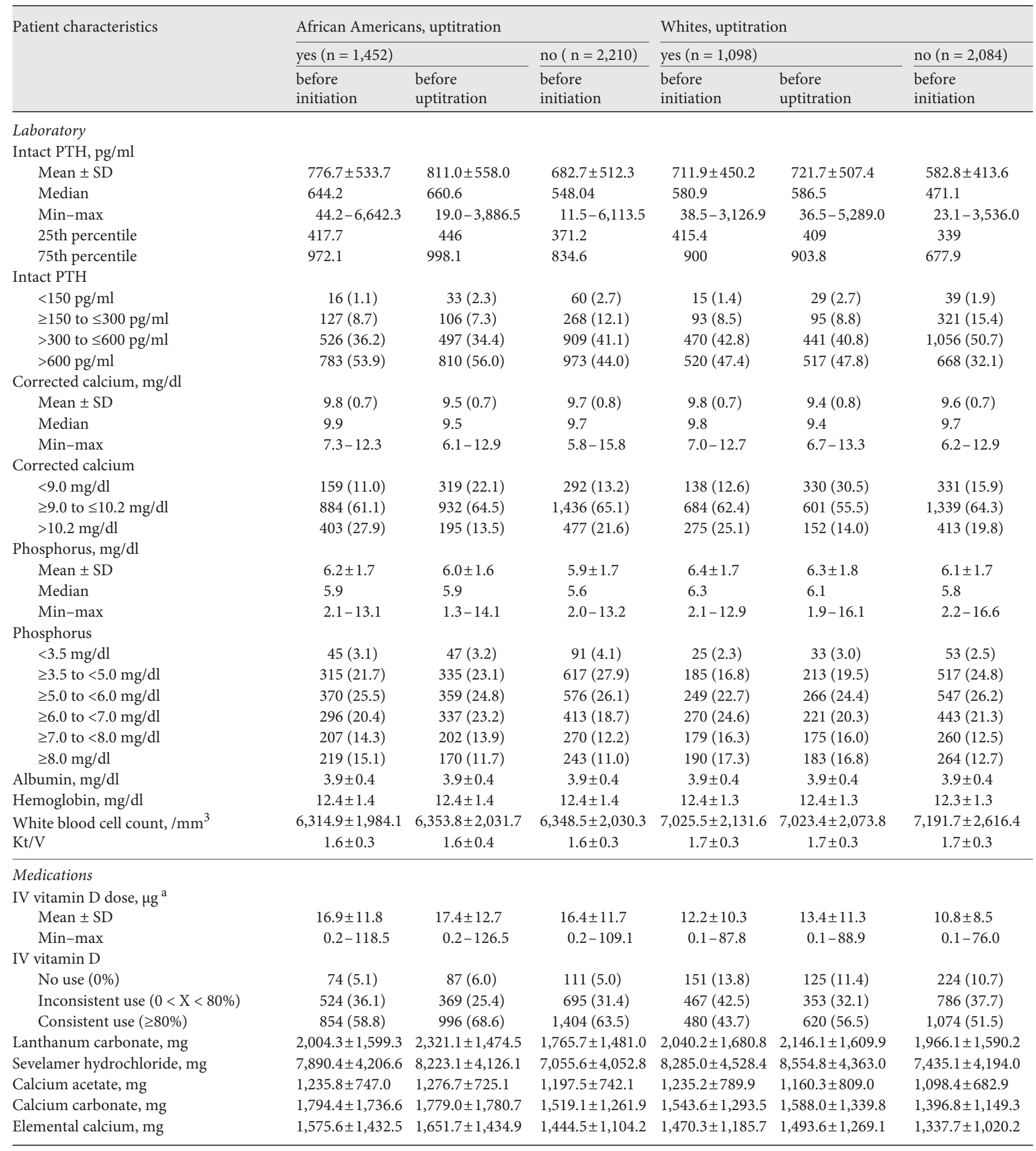

Values are mean $\pm \mathrm{SD}, \mathrm{n}(\%)$ or as indicated. ${ }^{\mathrm{a}}$ Weekly paricalcitol equivalent. 
Table 5. Laboratory characteristics and medications by race and cinacalcet discontinuation status within 12 months of initiation at the time of initiation and discontinuation

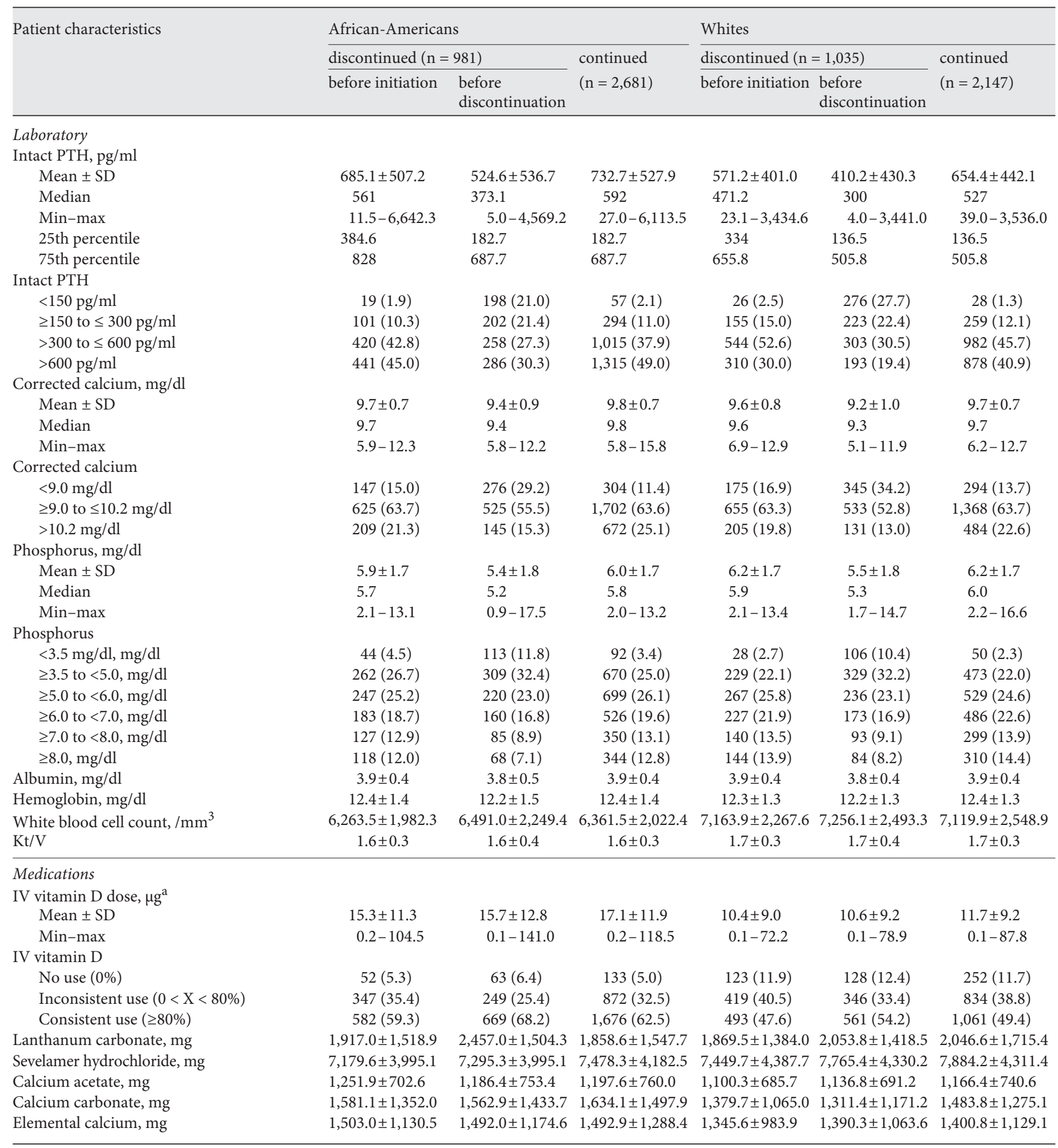

Values are mean $\pm \mathrm{SD}, \mathrm{n}(\%)$ or as indicated. ${ }^{\mathrm{a}}$ Weekly paricalcitol equivalent. 
among African-Americans who discontinued than among their counterparts who continued. After adjustment, there was a statistically significant interaction between race and intact $\mathrm{PTH}$ level at the time cinacalcet was discontinued ( $\mathrm{p}=0.048)$ (table 3 ). African-Americans in each PTH strata were less likely to discontinue, but the relationship appeared weaker among patients with intact $\mathrm{PTH}>600 \mathrm{pg} / \mathrm{ml}$ at discontinuation.

\section{Discussion}

In a large population of prevalent hemodialysis patients with 3 years of follow-up, we describe for the first time racial differences in cinacalcet use for SHPT. Overall, we report higher cinacalcet initiation among AfricanAmericans than among Whites. Further, greater SHPT disease severity in African-Americans was accompanied by higher and more consistent vitamin $\mathrm{D}$ use and more rapid disease progression, as reflected by changes in PTH level, among those who were later initiated on cinacalcet. Overall, African-Americans were more likely to receive cinacalcet prescriptions and to require higher doses, and less likely to have prescriptions discontinued. AfricanAmericans were slightly more likely to require dose uptitration, but this relationship lacked statistical significance

The greater severity of SHPT among African-Americans with ESRD as measured by higher levels of PTH has been previously described $[2,3,6]$. Our findings are consistent with these prior observations, including both higher levels of PTH and need for higher doses of IV vitamin D to treat SHPT in African-Americans. Our results extend these observations to describe higher use of cinacalcet among African-Americans in a large, geographically diverse population of hemodialysis patients.

The National Kidney Foundation's Kidney Disease Outcomes Quality Initiative (KDOQI) guidelines recommend treating SHPT to achieve PTH levels within a target range of $150-300 \mathrm{pg} / \mathrm{ml}$, and these guidelines were in effect during the timeframe of our study [11]. African-Americans had higher PTH levels and received higher doses of IV vitamin D and cinacalcet, most likely in the pursuit of this target range. The reasons for higher levels of PTH among African-Americans are poorly understood. Racial differences in the PTH/vitamin D axis have been demonstrated in populations without kidney disease; African-Americans have been found to have lower levels of urinary calcium [12], higher levels of 1,25-dihydroxyvitamin $\mathrm{D}_{3}\left(1,25(\mathrm{OH})_{2} \mathrm{D}_{3}\right)$, and lower levels of 25-hydroxyvitamin $\mathrm{D}_{3}\left(25(\mathrm{OH}) \mathrm{D}_{3}\right)$ [13]. Suggested explanations of these differences include decreased synthesis of $25(\mathrm{OH}) \mathrm{D}_{3}$ among African-Americans due to skin pigmentation, with subsequent development of SHPT [12, 13], and important allelic differences in vitamin $\mathrm{D}$ receptors that may result in more severe SHPT [14-16]. Among patients with ESRD, these differences persist and are most clinically apparent as differences in PTH level.

Regardless of biologic mechanism, the higher prevalence of SHPT in African-Americans is of great clinical concern given the higher mortality associated with more severe SHPT in ESRD patients [17] and observations that treatment of SHPT is associated with improved mortality [18], particularly among African-Americans [2]. Unadjusted results from the Evaluation of Cinacalcet Hydrochloride Therapy to Lower Cardiovascular Events (EVOLVE) trial showed that cinacalcet did not significantly reduce risk of death or major cardiovascular events in hemodialysis patients with SHPT, but this trial was not powered to specifically evaluate this endpoint in AfricanAmerican compared with white patients [19].

Particularly troubling, as we observed in this analysis, is that higher median PTH levels persist in African-Americans despite their receiving both cinacalcet and IV vitamin D over prolonged follow-up; the lack of achieved parity in PTH level between the two race groups suggests a difference in biology or a disparity in treatment, or both, and deserves further investigation. Possibly, higher PTH in African-Americans is biologically appropriate. Further research is needed to determine appropriate target PTH levels in patients of different races and ethnicities.

Management of SHPT among African-Americans also has important policy implications, as it remains to be seen whether racial differences in manifestations of SHPT will translate into inequitable clinical care as payment for cinacalcet and phosphate binding agents transition to the Prospective Payment System (PPS) in 2016. In our study, prescribed doses of cinacalcet were higher for AfricanAmericans than for Whites in every PTH strata. The differences in dose may not appear meaningful from a clinical standpoint; however, dialysis organizations with relatively higher proportions of African-American patients will face higher costs related to cinacalcet and other medications. In the capitated PPS system, African-American and white patients will receive care within the confines of equivalent provider reimbursement despite the higher medication requirements of erythropoietin to treat anemia [19] and IV vitamin D and cinacalcet to treat SHPT in African-Americans. 
The higher use of cinacalcet among African-Americans was not uniform. We observed interactions between race and various patient characteristics regarding cinacalcet initiation and discontinuation that deserve comment. The lower likelihood of younger African-Americans (ages 18-44 years) being initiated on cinacalcet compared with their white counterparts may reflect differences in medication prescription coverage; it has recently been shown that African-American patients are more likely to be enrolled in Medicare Part D and to have low-income subsidy status in each age bracket, including the bracket aged less than 44 years [20]. This factor should lead to both higher access to cinacalcet and higher likelihood of initiation, regardless of age. However, Medicare Part D coverage was not available until 2006; thus, the lower likelihood of cinacalcet prescription among younger African-American versus white patients in our study may reflect differential access to cinacalcet before Medicare Part D implementation. Or, it may simply reflect differential prescribing for younger African-American versus white patients. Unfortunately, we were unable to test these hypotheses, as the necessary data were not available for this analysis. Additionally, the lack of association between race and cinacalcet initiation or discontinuation among patients with intact PTH levels $>600 \mathrm{pg} / \mathrm{ml}$ may reflect the degree of perturbation of the PTH level and the importance of treating severe SHPT regardless of actual PTH level when it exceeds $600 \mathrm{pg} / \mathrm{ml}$. Similarly, among patients with corrected calcium level $>10.2 \mathrm{mg} / \mathrm{dl}$, the anticipated hypocalcemic effects of cinacalcet may supersede other factors that might influence medication prescription. By necessity, these explanations are somewhat speculative, as this analysis was not designed to determine the reasons for these relationships; these observations provide the foundation for future research.

The limitations of the study merit mention. As an observational study, this analysis cannot establish causeand-effect relationships and is subject to confounding from unmeasured factors. In particular, we were unable to account for prescription insurance status, which may have influenced medication choice. Given that we present an initial description of racial differences in clinical patterns of cinacalcet use, an important next step may be to define influential aspects of this relationship. This analysis benefits from well-delineated clinical data from DaVita combined with comprehensive administrative data from the United States Renal Data System, allowing adjustment for important and varied confounding variables such as comorbid conditions, laboratory data, and receiving phosphorous binders and IV vitamin D.
In this retrospective observational cohort study, we describe for the first time racial differences in cinacalcet use among patients with ESRD receiving hemodialysis. We found overall higher initiation of cinacalcet among African-American patients, characterized by higher initiating dose, higher likelihood of initiation, higher likelihood of uptitration, and lower likelihood of discontinuation compared with white patients. These findings have important implications for clinical care, particularly when considered in the context of the dialysis PPS. Given that race is not currently included as an adjuster for the PPS payment to dialysis providers, providers with a predominance of African-American patients may not be able to adequately treat these patients, who require higher doses of multiple medications to treat ESRD. Further work should focus on ensuring continued quality of care against a background of rapidly evolving reimbursement policies and on preventing inequities of care.

\section{Acknowledgments}

This study was supported by a research contract from Amgen Inc., Thousand Oaks, Calif., USA. The contract provides for the Minneapolis Medical Research Foundation authors to have final determination of manuscript content. The data reported here have been supplied by the United States Renal Data System (USRDS) and DaVita, Inc., with data linkage conducted by the USRDS. The interpretation and reporting of these data are the responsibility of the authors and in no way should be seen as an official policy or interpretation of the US Government. The authors thank Chronic Disease Research Group colleagues Pamela Giles for manuscript preparation and Nan Booth, MSW, MPH, ELS, for manuscript editing.

\section{Disclosure Statement}

Britt B. Newsome is employed by Denver Nephrologists, which receives research support from Amgen. Ryan D. Kilpatrick is employed by Amgen. Jiannong Liu, David Zaun, Craig A. Solid, and Kimberly Nieman are employed by the Chronic Disease Research Group, which receives research support from Amgen. Wendy L. St. Peter is employed by the University of Minnesota, College of Pharmacy, and conducts research with the Chronic Disease Research Group. 


\section{References}

1 Kiberd BA, Clase CM: Cumulative risk for developing end-stage renal disease in the US population. J Am Soc Nephrol 2002;13:16351644.

$>2$ Wolf M, Betancourt J, Chang Y, Shah A, Teng M, Tamez H, Gutierrez O, Camargo CA Jr, Melamed M, Norris K, Stampfer MJ, Powe NR, Thadhani R: Impact of activated vitamin D and race on survival among hemodialysis patients. J Am Soc Nephrol 2008;19:1379-1388.

$>3$ Kalantar-Zadeh K, Miller JE, Kovesdy CP, Mehrotra R, Lukowsky LR, Streja E, Ricks J, Jing J, Nissenson AR, Greenland S, Norris KC: Impact of race on hyperparathyroidism, mineral disarrays, administered vitamin $\mathrm{D}$ mimetic, and survival in hemodialysis patients. J Bone Miner Res 2010;25:2724-2734.

-4 Martins D, Wolf M, Pan D, Zadshir A, Tareen N, Thadhani R, Felsenfeld A, Levine B, Mehrotra R, Norris K: Prevalence of cardiovascular risk factors and the serum levels of 25-hydroxyvitamin D in the United States: data from the Third National Health and Nutrition Examination Survey. Arch Intern Med 2007;167:1159-1165.

5 Harris SS, Soteriades E, Coolidge JA, Mudgal S, Dawson-Hughes B: Vitamin D insufficiency and hyperparathyroidism in a low income, multiracial, elderly population. J Clin Endocrinol Metab 2000;85:4125-4130.

-6 Gupta A, Kallenbach LR, Zasuwa G, Divine GW: Race is a major determinant of secondary hyperparathyroidism in uremic patients. J Am Soc Nephrol 2000;11:330-334.

$>7$ De Boer IH, Gorodetskaya I, Young B, Hsu CY, Chertow GM: The severity of secondary hyperparathyroidism in chronic renal insufficiency is GFR-dependent, race-dependent, and associated with cardiovascular disease. J Am Soc Nephrol 2002;13:2762-2769.
-8 Block GA, Zaun D, Smits G, Persky M, Brillhart S, Nieman K, Liu J, St Peter WL: Cinacalcet hydrochloride treatment significantly improves all-cause and cardiovascular survival in a large cohort of hemodialysis patients. Kidney Int 2010;78:578-589.

$>9$ St Peter WL, Li Q, Liu J, Persky M, Nieman K, Arko C, Block GA: Cinacalcet use patterns and effect on laboratory values and other medications in a large dialysis organization, 2004 through 2006. Clin J Am Soc Nephrol 2009;4:354-360.

10 St Peter WL, Li S, Liu J, Gilbertson DT, Arneson TJ, Collins AJ: Effects of monthly dose and regular dosing of intravenous active vitamin D use on mortality among patients undergoing hemodialysis. Pharmacotherapy 2009;29:154-164.

11 National Kidney Foundation: K/DOQI clinical practice guidelines for bone metabolism and disease in chronic kidney disease. Am J Kidney Dis 2003;42:S1-S201.

12 Bell NH, Yergey AL, Vieira NE, Oexmann MJ, Shary JR: Demonstration of a difference in urinary calcium, not calcium absorption, in Black and White adolescents. J Bone Miner Res 1993;8:1111-1115.

13 Bell NH, Greene A, Epstein S, Oexmann MJ, Shaw S, Shary J: Evidence for alteration of the vitamin D-endocrine system in Blacks. J Clin Invest 1985;76:470-473.

14 Gupta A, Ozbirn T, Shanklin N, Warnock DG, Watson B: Vitamin D receptor gene polymorphism and secondary hyperparathyroidism (abstract). Nephrol Dial Transplant 1996;11:1215.
15 Yokoyama K, Shigematsu T, Tsukada T, Ogura Y, Takemoto F, Hara S, Yamada A, Kawaguchi Y, Hosoya T: Apa I polymorphism in the vitamin $\mathrm{D}$ receptor gene may affect the parathyroid response in Japanese with endstage renal disease. Kidney Int 1998;53:454458 .

16 Carling T, Kindmark A, Hellman P, Lundgren E, Ljunghall S, Rastad J, Akerstrom G, Melhus H: Vitamin D receptor genotypes in primary hyperparathyroidism. Nat Med 1995;1:1309-1311.

17 Tentori F, Blayney MJ, Albert JM, Gillespie BW, Kerr PG, Bommer J, Young EW, Akizawa T, Akiba T, Pisoni RL, Robinson BM, Port FK: Mortality risk for dialysis patients with different levels of serum calcium, phosphorus, and PTH: the Dialysis Outcomes and Practice Patterns Study (DOPPS). Am J Kidney Dis 2008;52:519-530.

18 Tentori F, Albert JM, Young EW, Blayney MJ, Robinson BM, Pisoni RL, Akiba T, Greenwood RN, Kimata N, Levin NW, Piera LM, Saran R, Wolfe RA, Port FK: The survival advantage for haemodialysis patients taking vitamin D is questioned: findings from the Dialysis Outcomes and Practice Patterns Study. Nephrol Dial Transplant 2009;24:963-972.

19 Ishani A, Guo H, Arneson TJ, Gilbertson DT, Mau LW, Li S, Dunning S, Collins AJ: Possible effects of the new Medicare reimbursement policy on African-Americans with ESRD. J Am Soc Nephrol 2009;20:1607-1613.

20 US Renal Data System: USRDS 2012 Annual Data Report: Atlas of Chronic Kidney Disease \& End-Stage Renal Disease in the United States, ed 2012. Bethesda, National Institutes of Health, National Institute of Diabetes and Digestive and Kidney Diseases, 2012. 